\section{Brian C. Bowen, MD, PhD}

$\mathrm{t}$ is with sadness that I am writing to inform the members of the ASNR of the death of our colleague Brian Bowen, MD, PhD (1946-2018).

Brian grew up in Southern California and graduated from Stanford University, where he majored in Chemical Engineering; subsequently, he obtained a $\mathrm{PhD}$ in Chemistry from the University of California, San Diego. Brian then entered the PhD-to-MD program at the University of Miami School of Medicine and graduated in 1983. Following a radiology residency and a fellowship in MR imaging at Mount Sinai Medical Center, Miami Beach, he was a neuroradiology fellow at the University of Miami/Jackson Memorial Hospital. Thereafter, he became a full-time faculty member, rising to the rank of Professor of Radiology.

Brian was an outstanding radiologist, teacher, and researcher and made major contributions to the field of MR imaging, among which were the development of MR images used in spectroscopy and techniques for the evaluation of spinal vascular malformations using MRA. He was held in high esteem by the radiology community both nationally and internationally; his contributions to the field were widely recognized, resulting in his election as President of the American Society of Spine Radiology (2006).

In this short communication, it is not possible to do justice to Brian's many accomplishments. Brian's work ethic, his contribu-

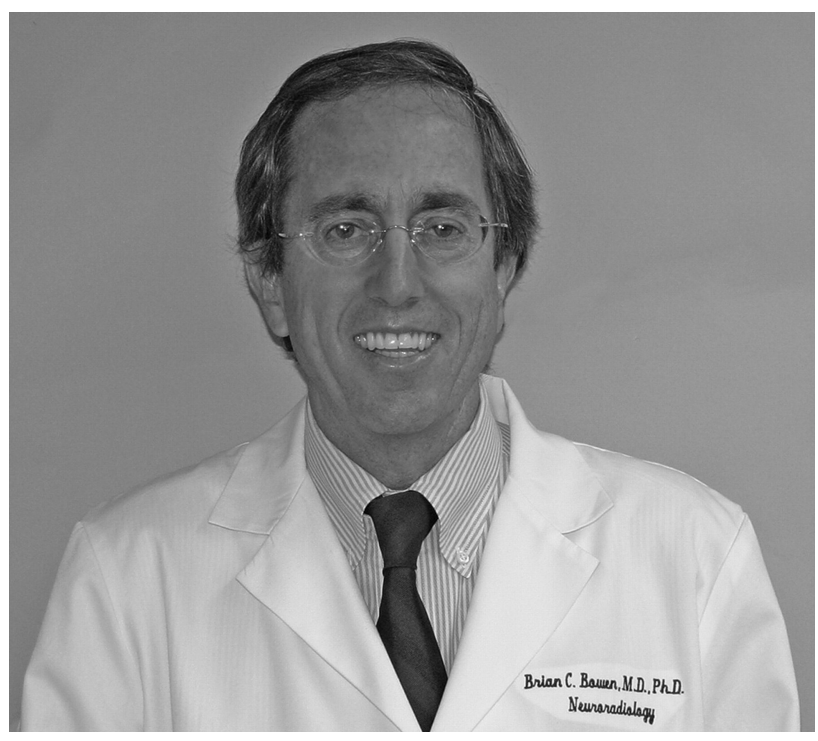

tions to the science of radiology, and his devotion to education were remarkable.

Brian is survived by his former wife Ana Campo, MD, and his 2 children, Katherine and Christopher.

(D) Robert M. Quencer, MD University of Miami School of Medicine Miami, Florida

http://dx.doi.org/10.3174/ajnr.A5683 